\title{
Dialectology an Interactional Overlap of Disciplines
}

\author{
Mortad-Serir Ilhem \\ Department of Foreign Languages: English, Tlemcen University, Tlemcen, Algeria \\ Email:mammoudham@yahoo.com
}

Received February $9^{\text {th }}, 2013$; revised March 11 $1^{\text {th }}$, 2013; accepted March 21 $1^{\text {st }}, 2013$

\begin{abstract}
Copyright (c) 2013 Mortad-Serir Ilhem. This is an open access article distributed under the Creative Commons Attribution License, which permits unrestricted use, distribution, and reproduction in any medium, provided the original work is properly cited.
\end{abstract}

\begin{abstract}
Dialectology has long been stereotyped as a limited scope of research since dialectologists long lived with the prejudice of being data collectors who amused their time to wander in rural meadows and converse with old peoples; and if there was any relationship between dialectology with other disciplines it was often viewed as intricate and sometimes controversial through many classificatory approaches. It is a false perception to view dialectology as autonomous discipline that inherits traditional dialect atlases; dialectology transcends the work on grounds to scrutinize the way linguistic variables function in speech. Since speech styles have social meaning that marks speakers' social and personal identity, dialectology as an illustrious field of research is related to many other disciplines to study the analysis of these markers: such as anthropology, folklore, linguistics, phonology, sociology, psychology, history, sociolinguistics, education and literature. This paper, thus, highlights the relationship of dialectology to other disciplines of language in linguistic studies like sociolinguistics and education.
\end{abstract}

Keywords: Dialectology; Sociolinguistics; Education; Dialect

\section{Dialectology and Sociolinguistics}

The very concern of this point refers to my once reading an article by Trudgill confessing that he changes the title of one of his first teaching conferences in 1970 from "Sociolinguistics and Dialectology" to "Sociolinguistics" without changing the content of the lecture. Since that Trudgill has changed a lot of his views towards dialectology via sociolinguistics and his second edition book with Chambers about dialectology justifies this in many ways.

It is said that there is certain hostility between sociolinguists mocking at dialectology as being an old discipline; and dialectologists defending against the newness of a science supposed to compete-or crash them down. Whether true or false my concern is rather to examine any co-operation within differences and similarities between the two fields of research because it is common to find dialectal variation in most language areas that has notably social implications.

Dialectology and sociolinguistics attempt to study language variation in different communities through representative results of a sample population. Though they differ in so many points as we will just see, they go in parallel with others because "for all their differences, dialectology and sociolinguistics converge at the deepest point. Both are dialectologies, so to speak. They share their essential subject matter. Both fix the attention on language in communities. Prototypically, one has been centrally concerned with rural communities and the other with urban centres, but these are accidental differences, not essential ones and certainly not axiomatic" (Chambers \& Trudgill, 2004: pp. 187-188). The two fields of research disconnect and meet together in different ways.

\section{Parallel Methodological Issues}

- Dialectology and sociolinguistics depend on fieldwork.

- Dialectology and sociolinguistics depend on recorded, instrumental analysis of data.

- Dialect geography, urban dialectology, and human geography are unified discipline. (Chambers \& Trudgill, 1998).

- Dialectology and sociolinguistics explicate access to language system of human knowledge.

- Dialectology and sociolinguistics infer language change from language variation.

\section{Separate Methodological Issues}

- Dialectology far pre dates Sociolinguistics in research and method of data collection.

- Dialectology is often referred to as traditional, geographical, and/or rural while sociolinguistics is rather an urban dialectology.

- Rural dialectology is concerned with spatial differences of language; urban dialectology is linking language with social features as age, gender, group, social class, and ethnic background.

- While dialectology tends to be diachronic at least in its beginning, sociolinguistics concentrates on a typical speech of a social group according to synchronic interest.

- Sociolinguistics studies the differences in language among members of speech community; dialectology is concerned with systematic study of language variants.

- Dialectological studies highlight the geographical range of linguistic facts; sociolinguistics focuses on their social as- 
pect.

- Sociolinguistics stimulates the social aspect neglected by linguistic theory; dialectology is rather concerned with measuring the special diffusion of dialect features conceptualized as dialectometry.

- Sociolinguistics involves social attitude and spatial community networks while dialectology considers the geographical dispersions of dialectal variants.

- Dialectologists preserve the linguistic varieties but sociolinguists succeed to divide them to variability.

Many of the sharing and non-sharing points, aforementioned between dialectology and sociolinguistics, have changed their direction of implication nowadays mainly because these two are speedily altering fields all along time. Therefore some concepts are renewed, others born anew to label both disciplines with innovative areas of research as shows the following section.

\section{Sociolinguistic Dialectology}

Undoubtedly, I am not sure which of sociolinguistics or dialectology has contributed to realize a rapid growth in many other related linguistic disciplines and to which extent the former sets up methods and approaches for the latter or vice versa; however, so often I have heard of the term sociolinguistics called urban dialectology or social dialectology but what merits one has for the other is heatedly discussed. The real nature of sociolinguistics/dialectology relationship results from competitive views sorted out of repetitive discussions; whatever view may be adopted, I am self confident that sociolinguistics since the 1960's has always developed to complement dialectology studies and many other language studies, hence, "sociolinguistics merits our attention just insofar as it signals an effort to change the practice of linguistics and other disciplines, because their present practice perpetuates a fragmented, incomplete understanding of humanity” Dell Hymes (1977: vii). Dialectology has now drifted towards the stream of several crucial topics that are updated like: urban dialects, speech community, and variability in language which enable dialectological research to investigate social factors such as age and gender. Sociolinguistics has special emphasis on dialectology which may develop values for both fields. Unlike traditional research studies, dialectology is no more restricted to rural, mountainous areas, or to old men only; it has now transcended to deal with women and city areas as well as like New York (Labov, 1966), Detroit (Wolfram, 1969), and Norwich (Trudgill, 1974), followed then by Glasgow (Macaulay, 1977), Edinburgh (Reid \& Romaine, 1978), and Belfast (Milroy, 1980). This has led to a new conceptualisation in language variation and change recently adopted by prolific researchers (Britain D., Trudgill P., Cheshire J., et al.) called sociolinguistic dialectology which reflects the growth of the discipline in multifaceted quests, naturally because the study of human language is a multidisciplinary field. Since dialect differences are not clearly qualitative but almost quantitative, sociolinguistic dialectology then compares between different neighbouring dialects assuming that one of the groups focuses on one dialectal feature more than others. Sociolinguistics brought new methodologies and applications to data analysis through collaborative efforts shared in common, "Trudgill thus notes that currently dialectologists and sociolinguists now seem to be moving towards 'a new ear of cooperation, integration and synthesis in the field'” (Bolton \& Kwok, 1992: p. 69) and that "one of the strengths of sociolinguistics and dialectology, or if you prefer, sociolinguistics including dialectology, is that this subject (or subjects) permits us to study language use, in reallife social contexts, both by social groups and by individuals” (ibid: 79).

Dialectology/sociolinguistics relationship is difficult and controversial since none of the two can do without the other in view of the fact that both fit for different fields of research in society and human real life unlike "a decade or two ago, it might have been possible to think that the common subject matter of dialectology and sociolinguistics counted for next to nothing. Now we know it counts for everything. Dialectology without sociolinguistics at its core is a relic. No serious perspective on dialectology can grant urban research and variation theory less than a central role” (Chambers \& Trudgill, 2004: p. 188). Notwithstanding many of elements that constitute the confluence of the discipline, a lot is still left to revitalise rural dialectology that continues to stimulate sociolinguistics field of research advocating a coherent single discipline-a wish that most of our scholars cited in this guidebook have pursued.

\section{Dialectology and Education}

Actually, there is much more interest in dialect study in schools than any other past time due to the development of dialectology as a data-oriented discipline that has proved uniqueness in its subdivision of linguistics. Long ago dialect speech inside the classroom looked inferior, a burning shame, or bitter say, a crime. Since then things have changed and opportunities to question and discuss problem-save in dialect are now clearly stated as a curricular right of children in schools. Teachers should be pleased by the basic linguistic competence brought by pupils to schools especially that "a child's background (intelligence, pre-school learning, home circumstances, parents, etc.) contributes approximately $85 \%$ to what is achieved in school. The other $15 \%$ is contributed by schooling” (Harrison, 1996: p. 9). This brings to reflection that any marginalization to the pupils' language, culture, and all that is involved may cause the failure in learning which may urge children to give up school. Moreover the tendency to devalue the child's first language or put it side-lined may make him lose confidence and feeble his powers in speech.

\section{Dialect Awareness in Schools}

Many groups linguistically debate whether to accommodate dialect differences with the standard in classroom or not. They struggle an intricate battlefield about the false misconception that Standard language is correct form and dialects are imperfect erroneous forms of the standard because they stem from ignorance and thus impede communication. Supporting this view, dialect has long been rejected out of school, from the part of the deficit position believing that "speakers of dialects with nonstandard forms have a handicap-socially and cognitively-because the dialects are illogical, or sloppy, or just bad grammar” (Adger et al., 2007: p. 17). Negative attitudes towards colloquial speech springs from prejudiced belief that dialects are linguistically inferior to standard language. For this reason many schools witnessed discrimination in the "cataloging" of groupclasses according to the pupils' cultural background and language; in many cases throughout the world students/pupils are either categorized with lower achievers or set in particular education classes because of their dialect speech features. Fortu- 
nately, this begins to disappear basically because other scholars, though they feel a minority, are convinced that dialect use in classroom does not erode the standard since there is no superior variety than another "because no one linguistic system can be shown to be inherently better, there is no reason to assume that using a particular dialect can be associated with having any kind of inherent deficit or advantage" (ibid: 18). Be that as it may, it is wise that educators should test ability and achievement through different varieties since dialect is not a deficient language, accordingly, "an understanding of the social attitudes and values concerning dialects and their speakers is thus essential for dealing with language differences” idem. Notwithstanding that dialect taught in classroom is not easy for many teachers it is more convincing for them that ignoring the dialect is a mistaken traditional judgment especially after what happened to the Oakland school where Ebonics the dialect of Black English was imposed as an instructional tool in the classroom. Since then, researchers expand lot of studies towards a policy to include dialect in the classroom. Therefore, dialect awareness in schools should be raised for the following reasons:

- Motivate children to use their knowledge in their first language to create a suitable educational environment.

- Using the language with all its varieties, be it standard or dialect is a good way of teaching accurately and appropriately in the classroom.

- Forbidding dialect in classroom leads to isolation and distaste.

- Explicate dialect variation at all the levels of grammar, phonology, and vocabulary, to improve the reading skills of children using different accents.

- The children's linguistic competencies should be used as a means and source for language development.

- Dialect discrimination is to be avoided from schools since all dialects are inherently equal.

- Standard language is one variety among others, and teaching it cannot be practical without all the varieties.

- Dialect differences have an effect on the quality of education received by some students both academically and socially (Labov, 1995) since research clearly supports the position that variation in language is a natural reflection of cultural and community differences (Labov, 1972).

- The use of the standard should be used in parallel with some conversational dialectal styles that help develop speaking and reading skills with the child.

- Correct form of language is governed by no rule or authority except the speaker's context, intention, and audience.

- Change is fundamental in all human languages that integrate language variation all the times in the entire world.

- Wherever there is dialect there should be geography, an area, a history, a society and a culture that can be kept alive through preserving it in its original vernacular dialect.

- Learning popular culture paves the way for children to know what constitutes a whole nation's heritage.

In fact the issue of nonstandard dialects in education is highly disputed, it is very well advanced in the United States and England and the whole Europe but less resolved in our country and the rest of the Arab world for the conviction that dialects do not fulfill communication's needs and consequently is not constructive. Many of scholars believe that dialect in schools is intricate because "the unchallenged position of the standard as the medium of education has seemed to necessitate savage and uncompromising attacks on the vernacular... spea- kers of British non-standard dialects were characterised as having 'evil habits of speech'” (Cheshire, 1989: p. 5). Dialects are not impediment to education but sources of better learning to the language which varies through time and space. As for English, teachers endeavour to teach the different pronunciations of words different from the standard as for "tin/ten, kin/ken" or "sinned/send" where /i/ and /e/ are pronounced the same in southern English dialects. African American vernacular dialect of English has been imposed in Oakland California School since December 1996 which has aroused increasingly prominent researches about dialect impact on the children's academic success, developing resources for teachers, solving the dilemma home/language in a non contrastive way, permitting children's use of home varieties in the classroom. After continuing conflicts about Ebonics, the latter succeeds to be "a legitimate linguistic system, different from the standard English system, Oakland schools use students' knowledge of Ebonics in teaching Standard English. In this way, the schools respect and exploit students' linguistic competence as a resource for language development rather than a deficit” (Adger et al., 19/20). The event took place in 1979 when African American parents complained to Ann Arbour Court in Michigan that their children were neglected by the educational system of the town "William Labov presented evidence showing that African American Vernacular English was a systematic, rule-governed linguistic variety. The court ruled that the education system should take account of the fact that children came to school speaking a structured language variety which is linguistically different from Standard English” (Trudgill, 2003: p. 8). Educators are more aware about dialect differences that can interfere in education exactly the same for "Ebonics a synonym for AAVE is considered as the primary language of African American children, and to take into account in their language arts lessons” (Nero, 2006: p. 7). Diverse linguistically students are found and teachers should be well equipped to face such population "once students who speak diverse varieties and creoles are in the classroom, teachers are faced with choosing effective resources, materials, and strategies for teaching them” (ibid: 13).

Any dialect is by and large a systematic rule-governed like any other natural speech varieties and it is no more accepted to judge or misjudge a dialect as ungrammatical, misspelled, slang, distorted, lazy, imperfect, erroneous and corrupting exactly as it is no more convenient to think that earth is flat. Therefore, it is most important for educators to understand that there are many advantages to dialect variation that have proved scientific, so any helping strategy to raise dialect awareness inside classroom can only be beneficial for a good learning of the standard itself since the learner can distinguish dialect patterns from the standard formal ones through ultimate comparison between the two rather than purposeful marginalization of the former. The child should be permitted to use some of the nonstandard forms while writing in the standard language as Trudgill calls bidialectism a policy successfully applied in Switzerland, and Norway; it is "an educational policy which is intended to give pupils who are not native speakers of the standard language proficiency in writing in the standard language while respecting and helping to maintain their local nonstandard dialects” (Trudgill, 2003: pp. 14-15). The policy is now stimulating the interest of many educators and practitioners in whole Europe.

Dialectology is an ongoing field of research heavily empirical, in which the process of development as a discipline was only related to both the revitalization of dialect geography and 
the rise of sociolinguistics. So many books about it have known reprints in order to give them a more up-to-date looks. Dialectology has now become an institutionalized academic discipline which has been expanded in various methodological issues beginning by its representatives: Jules Gilliéron who studied the history of the word and Louis Gauchat who favoured the phonetic evolution of it till today's prolific researchers who mainly contribute to conceptualize notions in dialectology that are still shaken. Accordingly, dialectology is not an autonomous field of research nor would linguistic theories develop without the contribution of dialectological studies.

\section{REFERENCES}

Adger, C. T., Wolfram, W., \& Christian, D. (2007). Dialects in schools and communities (2nd ed.). Routledge: Taylor and Francis Group.

Bolton, K., \& Kwok, H. (1992). Sociolinguistics today: International perspectives. England: Routledge.

Chambers, J.K., \& Trudgill, P. (2004). Dialectology (2nd ed.). Cam- bridge: Cambridge Textbooks in Linguistics.

Cheshire, J. (1989). Dialect and education: Some European perspectives. Multilingual matters.

Harrison, C. (1996). Methods of teaching reading: Key issues in research and implications for practice. Interchange, N39. The Scottish Office Education and Industry Department (SOEID). Edinburgh: GNP Booth Ltd.

Hymes, D. (1977). Foundations in sociolinguistics: An ethnographic approach. Routledge: Taylor and Francis.

Labov, W. (1972). The logic of nonstandard English. In W. Labov (Ed.), Language in the inner city: Studies in the Black English vernacular. Philadelphia: University of Pennsylvania Press.

Labov, W. (1995). Can reading failure be reversed: A linguistic approach to the question. In V. Gadsden, \& D. Wagner (Eds.), Literacy among African-American youth: Issues in learning, teaching, and schooling (pp. 39-68). Cresskill, NJ: Hampton.

Nero, J. S. (2006). Dialects, Englishes, Creoles, and education. England: Routledge.

Trudgill, P. (2003). A glossary of sociolinguistics. Oxford: Oxford University Press. 